\title{
М MILITARY PSYCHOLOGISTS NECESSARY AS SERBIAN SOLDIERS PREPARE FOR PEACEKEEPING MISSIONS
}

\author{
Radojka Dražić \\ University of Defense in Belgrade, Military Academy
}

This paper advocates the participation of the military psychologists in peacekeeping missions. It has compared the peacekeeping mission tasks performed by the military psychologists in the Serbian and Austrian Armed Forces and it has highlighted the main differences. The conclusion is that the engagement of the military psychologists in the preparatory work of the Serbian Armed Forces members should be increased, and the military psychologists should participate in peacekeeping missions or be given the opportunity to collect data in the field. Additionally, it would be useful to study the selection process and preparatory programs for peacekeeping mission participants in the Nordic countries and the USA.

Key Words: peacekeeping mission, Serbian Armed Forces, psychological preparation, military psychologist, United Nations

\section{Introduction}

The experience of the Serbian Armed Forces medical corps in the UN peacekeeping mission in the DR Congo has demonstrated a significant need for the military psychologists. The most common problems faced by soldiers who returned to Serbia in 2006 were caused by psychological issues. These problems were important in $20 \%$ of the cases according to the data from this mission.

Military observers are exposed to extraordinarily stressful conditions. To be in an extremely uncertain situation leads to tensions and irritation, and frequently this "daily" stress can accumulate and result in more chronic complications. Long-term stress can lead an individual to have problems with his or her environment and into depression. Strong and sudden psychological or physical events can cause "traumatic" stress. Soldiers must also deal with "post-traumatic" stress, which is caused by "long-term consequences after one or more episodes of traumatic stress."

The most important stress factors are "difficult and complex tasks, a lack of professional training, intolerance of the locals, insecurity, stress caused by the presence of the armed men, everyday repression of emotions, lack of privacy, separation from family members and friends, cultural differences, language problems, and lack of recreation."1

\footnotetext{
${ }^{1}$ Serbian Armed Forces Peacekeeping Operations Center, MONUC, AMET 9, May-November 2007.
} 
After their experience in Congo, the Serbian Armed Forces medical corps concluded that psychological readiness is the key factor for successful conduct of mission tasks and an important determinant in significantly minimizing (or multiplying) risk factors."

15 people have come back with neurological problems, 12 with bone fractures, 11 with heart conditions, 9 with tuberculosis, 6 with diabetes, 5 with epilepsy, 3 with cancer, 2 with dermatological problems and 1 with hepatitis. ${ }^{3}$

\section{Peacekeeping mission tasks performed by psychologists in the Serbian Armed Forces}

Currently, psychologists have two main tasks regarding peacekeeping missions: they participate in the selection process of future Serbian Armed Forces mission participants and their preparatory program. Experts from the Air Medical Institute (Academy for Military Medicine) conduct the selection and in addition to the standard interview they test the candidates' personality, focusing on their ability to adapt to difficult situations and resist stress. Candidates are subjected to complete somatic and toxicological testing, meaning that those who are successful will not suffer from any psychosomatic disease or be addicted to psychoactive substances. Psychologists from the Institute prepare the list of candidates on the basis of all test results. ${ }^{4}$

The psychologists from the General Staff Human Resources Department provide training in psychological preparation. They are engaged in individual conversations with potential participants in peacekeeping missions and they focus on the questions of how to overcome stress, panic attacks and fear. They pay particular attention to possible personal and family problems and to those personality aspects significant for successful interpersonal relations. ${ }^{5}$

\section{Tasks of Austrian Armed Forces military psychologists regarding peacekeeping missions}

In 1999 the Austrian Armed Forces established the position of a military psychologist at a battalion level. This officer provides support during periods of selection and preparation, as well as during peacekeeping mission and afterwards. The Human Resources Agency, which is directly responsible to the Ministry of Defense, selects the candidates. One of the main goals of this Agency is to "decrease the risk for soldiers and their surroundings during military operations" (Ebner, 2007 a:10). Its scope of work includes recruitment, selection and making final decisions on candidates for peacekeeping missions.

Selection criteria are social intelligence, attention and concentration, stress resistance and social integration abilities.

\footnotetext{
${ }^{2}$ Ibid.

${ }^{3}$ Ibid. 33

${ }^{4}$ Data collected during an interview with the psychologist from the Air Medical Institute (Academy for Military Medicine), January 22, 2008.

${ }^{5}$ Data collected during an interview with the psychologist from the Serbian Armed Forces General Staff Human Resources Department, February 19, 2008.
} 
Military Psychologists Necessary as Serbian Soldiers Prepare for Peacekeeping Missions

The selection procedure includes three components:

- The first one is a written test that is three and a half hours long and it consists of sections examining intelligence, concentration and attention, personality and health condition.

- The second trial is a "bunker test," which examines group dynamics, stress resistance and social integration abilities. This test simulates psychologically stressful situations. Candidates have to spend 13 hours continuously in the bunker without sleep, food or cigarettes. Observers monitor each candidate's behavior and measure his or her stress level.

- The third component is a psychological interview. On the basis of these three tests, it is possible to make a decision about the candidate's capabilities to participate in peacekeeping mission. ${ }^{6}$

Future participants work on anti-stress techniques and they are trained to minister psychological assistance to themselves and others.

Commanders receive different psychological training than the other soldiers. For three days they work in small groups, discuss general issues such as situations that are difficult to manage, a perfect leader's personality, appropriate behavior during peacekeeping missions abroad, conversational skills, work as a part of a crisis staff, conduct complex individual conversations, cope with death and serious injuries, handle the extension of peacekeeping missions, techniques for accepting new members into the group, and self-reflection.

All soldiers have to be present at introductory lectures ${ }^{7}$ in the following fields: general stress, military intervention stress, measures against stress, traumatic stress, posttraumatic disorder, psychological self-help and helping other colleagues. Group exercises mostly focus on discussions about the experience of peacekeeping mission veterans, coping with stress and practical training in relaxation techniques. Before a team travels abroad it performs a final exercise as part of the overall training process, which is monitored by a military psychologist. This exercise lasts for two weeks and includes an emphasis on different skills such as behavior during demonstrations, implementation of security measures, search for vehicles and individuals, etc. It is the job of psychologists to emphasise possible problems that could appear as participants conduct these tasks and they explain how to resolve them. The point of the battalion psychologist's engagement during preparations for the mission is to establish trust between him/her and the staff. During this phase, the psychologist should note the work style and potential problems of each soldier. The psychologist should identify the problems in advance, point them out to the commander, formulate a strategy and the eventual activities for addressing them.

The Austrian military psychologists also prepare a special brochure that informs soldiers about the potential problems they may face during the mission, noting the various stress factors, and particularly providing advice on how to deal with kidnapping or prison situations. It is important to prepare family members for both separation from their loved ones and the soldier's return from his/her mission.

The brochure includes a "list of critical situations" with explanations of potential incidents, possible physical and psychological reactions and measures for their prevention.

\footnotetext{
${ }^{6}$ The Austrian Armed Forces Preparation Center (ZEV) plans and conducts training sessions to prepare soldiers for their missions.

${ }^{7}$ Data based on Peacekeeping Mission description on Kosovo AUCON10/KFOR 2004 (April-October) according to Ebner, 2007a.
} 
In the Austrian Armed Forces the military psychologist participates in the actual peacekeeping missions. They are responsible for the soldiers' psychological treatment and their cooperation with the commander, priest ${ }^{8}$, doctor, personal adviser and lawyer.

This psychological support includes special counseling in relation to individual and group problems and interventions in crises.

Urgent psychological measures should be taken as soon as possible, especially in the cases of car accidents, suicide attempts, severe injuries or crippling. In the case of hospitalization, a psychologist is obliged to take care of soldiers while they are in the hospital.

The military psychologist informs the commander and the staff about the troops' psychological condition (psychological climate) and highlights potential factors that could lead to changes. They can warn about possible consequences of specific orders and explain some basic psychological causes in order to elucidate soldiers' comportment in the best way. The psychologist makes a weekly report on the contingent's psychological condition, advises the commander during crises and offers solutions for overcoming problems. In cases when it is not possible to solve a problem, the psychologist can dismiss a soldier from the mission and justify this action in a written diagnostic report. Interestingly, the psychologist also participates in conversations with national and international representatives during official visits to the mission.

\section{Main differences of military psychologists' work in Serbian and Austrian Armed Forces peacekeeping missions}

While the Serbian military psychologists participate only in the selection and preparation phases, the Austrian psychologists participate in the mission itself, and that is the main difference between these two armies' practices. The second difference are longer and more complex selection and preparation phases in the Austrian Armed Forces, and therefore psychologists' tasks are more difficult. The qualifications required of the Austrian military psychologists involved in peacekeeping missions are rigorous. In addition to mastering clinical, health and urgent psychology and the psychology of work, a military psychologist must be a stable and healthy individual, having passed an obligatory general physical and psychological examination.

They should have practical experience in therapy and counseling, be fit for teamwork and cooperation, and display empathy, an analytical way of thinking and flexibility in new situations.

Having the military education is not required at present, but will be eventually since it will facilitate psychologists' work and their relations with other participants in the mission.

If the psychologist has the military background, communication with the commander will be easier. The knowledge of English is also necessary. During seven days of preparations for peacekeeping missions psychologists' special training covers a variety of general and special skills. The psychologist is trained how to write a report from the field, taught which information they should send to their home country and briefed on telephone communication rules. The training covers the experience of other psychologists' work in the field, particularly examining those who were unsuccessful and had to return from their missions early. Military psychologists' success in preparing members of the

\footnotetext{
${ }^{8} \mathrm{~A}$ priest is an obligatory member of the Austrian battalion and his task is to prevent post-traumatic reactions.
} 
armed forces for peacekeeping missions depends on several factors. A solid academic background and special additional training are required.

However, in order to be able to give the best advice, it is necessary that the military psychologists have insights into the military observers' tasks and the conditions in which those duties must be performed.

Information exchange between field doctors and psychologists in the target country is particularly valuable. Specialized foreign literature can also be a useful source of knowledge. Due to the importance of psychologists' special knowledge and the cultural characteristics of the country that military observers come from, military psychologists can get the most complete data only from their own observations.

\section{Conclusions and recommendations}

A) Military psychologists' engagement in the preparation phase of sending the Serbian Armed Forces members to participate in peacekeeping missions should be increased. The small group "anti-stress program" should become obligatory considering the high risk from stress and the possible consequences of not dealing with this problem. Staff should be trained to help themselves and the other members of the mission. Seminars organized for spouses who stay at home could be very useful because they would help improve communication within families. Additional psychological work on relationship problems could significantly improve the Serbian Armed Forces members adaptation to the challenges of peacekeeping missions.

B) The military psychologists should participate in peacekeeping missions or in research teams in order to collect data about the concrete positions in the mission. They also need information about how individuals cope in the mission. For the time being, the Serbian Armed Forces military psychologists get only subjective assessments from the people who have participated in the mission. It would be extremely useful for psychologists to be present during the first month of the mission or to visit the national contingent in the field if and when it is needed.

C) Studying other selection and preparation programs would be also useful. The participation of military psychologists in peacekeeping missions is a neglected issue. Besides the Austrian experience, it would be interesting to examine the Nordic and the US practices. Such analyses would improve our understanding of the role of the military psychologists in peacekeeping missions.

The qualitative work of the military psychologists can improve the quality of the Serbian Armed Forces participants in peacekeeping missions and also ensure the improvement to a level that would facilitate the active participation in the Partnership for Peace and NATO. Peacekeeping missions is not only the military, but also a political issue since it engages our country in the process of ensuring the regional and world stability. Moreover, it is one of our obligations as the UN member.

\section{References}

[1] Centar za mirovne operacije VS, MONUC, AMET 9, Maj-Novembar 2007.

[2] Ebner, Georg (2007a) «Psychologische Betreuung im Auslandseinsatz am Beispiel Kosovo», Sonderpublikation. Wien: Schriftenreihe der Landesverteidigungsakademie.

[3] Ebner, Georg (2007b) «Soldatisches Identitatsprofil und psychosoziale Implikationen», Wien: Schriftenreihe der Landesverteidigungsakademie.

[4] Serbian Armed Forces, http://www.vs.rs 